\title{
Etch Rate and Dimensional Accuracy of Machinable Glass Ceramic in Chemical Etching
}

\author{
Ting Huey Tze ${ }^{1, a}$, K.A. Abou-El-Hossein ${ }^{2, b}$, Chua Han Bing ${ }^{1, c}$ \\ ${ }^{1}$ Curtin University of Technology (Sarawak Campus), 98009 Miri, Sarawak, Malaysia. \\ ${ }^{2}$ Department of Mechatronics, Nelson Mandela Metropolitan University, Port Elizabeth 6031, South \\ Africa. \\ aahwai_ting@hotmail.com, ${ }^{b}$ Khaled.Abou-El-Hossein@nmmu.ac.za, ${ }^{c}$ chua.han.bing@curtin.edu.my
}

Keywords: Chemical etching, Machinable glass ceramics, design of experiment

\begin{abstract}
Machinable glass ceramic (MGC) has been well known in the micro-electromechanical system and semiconductor industry. Chemical etching is used in this experiment to study the performance of MGC. This study includes etching rate of MGC and it accuracy by indentation method, which is considered new in the industry. The categoric parameter applied here is the type of chemical etchant: hydrochloric $(\mathrm{HCl})$, hydrophosphoric $\left(\mathrm{H}_{3} \mathrm{PO}_{4}\right)$ and hydrobromic $(\mathrm{HBr})$ acids; and, numerical parameters are etching temperature and etching solution. This experiment investigation is governed by design of experiment (DoE) and predictive models for each etchant are generated.
\end{abstract}

\section{Introduction}

Machinable glass ceramic (MGC) has a diverse range of applications in micro- and nanotechnology fields including optics, microelectromechanical system (MEMS), micro-total analysis system (u-TAS) [1]. MGC has been known as optimum material combining the performance of a technical ceramic with the versatility of high performance plastic. MGC exhibits low fracture toughness, good short-term clinical performance, biocompatibility and cost effectiveness. In term of industry wise, MGC presents high precision and complicated form capability, it is also excellent in design flexibility, which allows design to be changed easily [2-4]. The main drawback of this material is its brittleness and sensitivity to flaws.

Recently, the demand of multi-kind and small quantity production has increased in the market. A more effectively and cost effective method is required to meet the increasing demand. In addition, researches have been trying to overcome photoresist/mask during etching, such as photoresist/mask adhesive problems [5, 6], undercut problems and compatibility of mask to solution used [7, 8]. Chemical etching with micro-indentation method has been introduced in the last few years [9-11]. The key point of this technology is the etching rate arising from the indentation. This technology is based on the etching rate difference between indented and non-indented area. Youn and Kang [12] fabricated micro-pattern on Pyrex glass with hydrofluoric acid etching and indicated the possibility of fabrication of glasses by this method. Saito et. Al. $[9,10]$ generated a micro-structure on advanced ceramics by combining chemical etching and micro-indentation method to form the patterning on glass.

In this paper, we are presenting the etching rate and dimensional accuracy of MGC in different chemical etchant, DA includes the undercut and ER of indented area. Last but not least, we are verifying the optimum variables and relationship between parameters and each output. 


\section{Experimental Procedure}

Each material is cut into $10 \mathrm{~mm} \times 10 \mathrm{~mm}$ X $10 \mathrm{~mm}$ dimension undergone an indented process as shown in figure 1a. Then, it is being cleaned in distilled water and baked for two hours. Substrates are etched in different concentrated chemical etchants at desired duration. The etching process is carried in boron silicate glass, which is displayed in figure 1b. After etching, substrates are cleaned or neutralized in continuous distilled water for half and hours. Last step is baking the substrates and evaluation is done afterward.

Precaution measure that is taken in etching process is etching temperature. This is due to the unstable voltage, causing the temperature changed from time to time. Thus, extra caution is required to make sure the etching temperature is not slip too far away from the desired parameter. A temperature controller is specially designed for this purpose and attached to the heating mantle. With tolerance of $\pm 5^{\circ} \mathrm{C}$, the heating mantle is turning on and off to maintain the desired temperature. Besides, measurement by thermocouple is done every 10minutes from the above access.

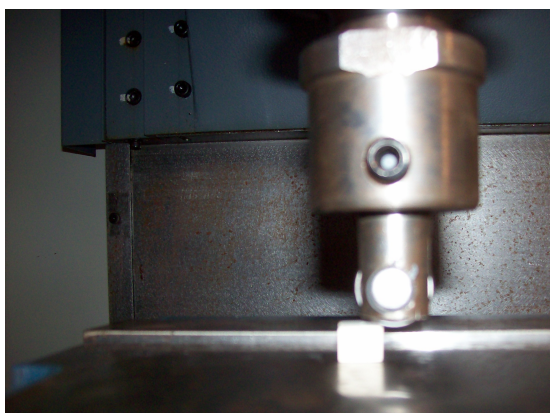

Fig. 1. Indentation of MGC

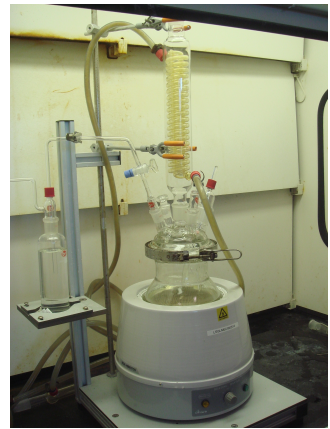

Fig. 2. Etching setup

\section{Materials}

$\mathrm{MGC}$ is the substrate in this experiment. MGC contains $46 \% \mathrm{SiO}_{2}, 16 \% \mathrm{Al}_{2} \mathrm{O}_{3}, 17 \% \mathrm{MgO}, 10 \% \mathrm{~K}_{2} \mathrm{O}$ and $7 \% \mathrm{~B}_{2} \mathrm{O}_{3}$. This material is produced by GoodFellow. Inc.

\section{Response Surface Methodology (RSM)}

Response surface methodology (RSM) is a computational statistical approach that is used to design experiments. It has been famously used in the industry due to its flexibility and accuracy. Central composite design (CCD) is type of RSM and this is applied here. Advantages of CCD are it allows all optimum variables take place simultaneously and it requires least number of testing compared to other design method. In this process, CCD generated 12 set of runs for each experiment (each chemical etchant). Total of three sets of experiments are carried out for three materials. ANOVA data is generated to evaluate the whole experiments. $P$-value is used to determine the significance of each variable. With lower magnitude of $p$-value, the variable is considered to be more important. CCD used in this experiment is managed by Design Expert 7.0.

Variables included etching temperature, etching duration and chemical etchant. Three type of chemical etchant are $\mathrm{HCl}, \mathrm{H}_{3} \mathrm{PO}_{4}$ and $\mathrm{HBr}$ acids. Range of etching temperature and etching duration is decided in first order model by $2^{\mathrm{k}}$ factorial design. $2^{\mathrm{k}}$ factorial design is a linearity design method that makes sure each of the selected variable fall in the desirable range, which lead us to the behavior of the process.

\section{Results}


Table 1-3 show ANOVA for etching rate generated by CCD in different solutions. It is found that all etching processes are fitted well into quadratic model with no lack of fit. In $\mathrm{HCl}$, both variables are found to be significant. The quadratic model in $\mathrm{HCl}$ in fitted $99.99 \%$ and all variables obtain less than $0.0001 p$-value. ANOVA of the etching rate in $\mathrm{HBr}$ shows that etching temperature is the most significant factor in $\mathrm{HBr}$, which is $98.8 \%$ fitted to quadratic model as recommended by $\mathrm{DE} 7$; and, etching duration (0.0007 $p$-value) and interaction between etching temperature and etching duration ( $0.0154 p$-value) appear to be the main variables in $\mathrm{H}_{3} \mathrm{PO}_{4}$ etching process.

Fig. 3 show the etching rate vs etching temperature with negative slope. Fig. $3 \mathrm{a}$ and $3 \mathrm{~b}$ depicted minimum etching rate that takes place at $40^{\circ} \mathrm{C}$ and increases immediately until chemical etchant boiling point. However, fig. $3 \mathrm{c}$ is slightly different and least etching rate occurs $\mathrm{H}_{3} \mathrm{PO}_{4}$ boiling point. This might be the reason why etching temperature is the least significant factor (in table 3). Fig. 4 presents etching rate vs etching duration in concentrated etchants. In fig. $4 a$ and $4 b$, negative slopes are obtained. In contrary, positive slope is obtained in fig. $4 \mathrm{c}$ with maximum etching rate happens between 220-230minutes. For fig. $4 \mathrm{a}$ and $4 \mathrm{~b}$, it is found that highest etching rate occurs at a shorter duration of etching, and the slope bounds back after 185 minutes for $\mathrm{HCl}$ and 165 minutes for $\mathrm{HBr}$ etching.

In dimensional accuracy, we investigated the undercut and depth of the indented area. It is found that different variables affecting dimensional accuracy in different types of chemical etchant. Table 4-6 show ANOVA for dimensional accuracy in $\mathrm{HCl}, \mathrm{HBr}$ and $\mathrm{H}_{3} \mathrm{PO}_{4}$ etching. $\mathrm{HCl}$ etching and $\mathrm{HBr}$ etching are fitted well in quadratic model with $97.42 \%$ and $96.16 \%$. In $\mathrm{HCl}$, temperature is found to be significant variable with optimum temperature occurring around $75-80^{\circ} \mathrm{C}$ (in fig. $5 \mathrm{a}$ ). In table 5 , etching duration is indicated as the main factor with a positive slope reaching 200minutes. Dimensional accuracy in $\mathrm{HBr}$ shows a slightly special case, whereby maximum dimensional accuracy happens at $75^{\circ} \mathrm{C}$ with maximum etching duration (240minutes). Fig. $6 \mathrm{~b}$ shows that etching duration of $\mathrm{HBr}$ etching supposes to be extended because linear slope is obtained in this analysis. In $\mathrm{H}_{3} \mathrm{PO}_{4}$ etching, it shows $95 \%$ fitness to quadratic model with etching duration as the main factor. According to fig. $5 \mathrm{c}$, maximum dimensional accuracy happens at it boiling point and peak etching rate at 135 minutes.

Table 1. Etching rate ANOVA for $\mathrm{HCl}$ etching.

\begin{tabular}{|l|l|l|l|l|l|}
\hline \multicolumn{5}{|c|}{ ER ANOVA for Response Surface Quadratic Model in $\mathrm{HCl}$} \\
\hline Source & Sum of Squares & $\begin{array}{l}\text { Mean } \\
\text { Square }\end{array}$ & $\begin{array}{l}\text { F } \\
\text { Value }\end{array}$ & p-value & \\
\hline Model & 3.19 & $6.40 \mathrm{E}-01$ & 162.37 & $<0.0001$ & Significant \\
\hline A-temperature & $6.30 \mathrm{E}-01$ & $6.30 \mathrm{E}-01$ & 160.79 & $<0.0001$ & \\
\hline B-period & $1.95 \mathrm{E}+00$ & $1.95 \mathrm{E}+00$ & 495.37 & $<0.0001$ & \\
\hline $\mathrm{A}^{\wedge} 2$ & $1.90 \mathrm{E}-01$ & $1.90 \mathrm{E}-01$ & 48.04 & 0.0004 & \\
\hline $\mathrm{B}^{\wedge} 2$ & $8.00 \mathrm{E}-01$ & $8.00 \mathrm{E}-01$ & 204.33 & $<0.0001$ & \\
\hline Lack of Fit & $1.10 \mathrm{E}-02$ & $3.75 \mathrm{E}-03$ & 0.91 & 0.5305 & not significant \\
\hline
\end{tabular}

Table 2. Etching rate ANOVA for $\mathrm{HBr}$ etching.

\begin{tabular}{|l|l|l|l|l|l|}
\hline \multicolumn{5}{|c|}{ ER ANOVA for Response Surface Quadratic Model in HBr } \\
\hline & Sum of Squares & $\begin{array}{l}\text { Mean } \\
\text { Square }\end{array}$ & F Value & p-value & \\
\hline Model & $9.53 \mathrm{E}-07$ & $1.91 \mathrm{E}-07$ & 19.4 & 0.0012 & significant \\
\hline A-temperature & $8.47 \mathrm{E}-07$ & $8.47 \mathrm{E}-07$ & 86.21 & $<0.0001$ & \\
\hline B-period & $3.03 \mathrm{E}-08$ & $3.03 \mathrm{E}-08$ & 3.08 & 0.1296 & \\
\hline A^2 & $2.24 \mathrm{E}-07$ & $2.24 \mathrm{E}-07$ & 22.84 & 0.0031 & \\
\hline Lack of Fit & $4.10 \mathrm{E}-08$ & $1.37 \mathrm{E}-08$ & 2.28 & 0.2581 & not significant \\
\hline
\end{tabular}


Table 3. Etching rate ANOVA for $\mathrm{H}_{3} \mathrm{PO}_{4}$ etching.

\begin{tabular}{|l|l|l|l|l|l|}
\hline \multicolumn{5}{|c|}{ ER ANOVA for Response Surface Quadratic Model in $\mathrm{H}_{3} \mathrm{PO}_{4}$} \\
\hline Source & Sum of Squares & $\begin{array}{l}\text { Mean } \\
\text { Square }\end{array}$ & F Value & p-value & \\
\hline Model & $1.57 \mathrm{E}+05$ & 31471.19 & 16.08 & 0.002 & significant \\
\hline A-temperature & 7776 & 7776 & 3.97 & 0.0933 & \\
\hline B-period & 80852.53 & 80852.53 & 41.32 & 0.0007 & \\
\hline AB & 21992.89 & 21992.89 & 11.24 & 0.0154 & \\
\hline$B^{\wedge} 2$ & 46391.07 & 46391.07 & 23.71 & 0.0028 & \\
\hline Lack of Fit & 1172.35 & 390.12 & 96.83 & 0.1000 & not significant \\
\hline
\end{tabular}

Table 4. Dimensional accuracy ANOVA for $\mathrm{HCl}$ etching.

\begin{tabular}{|l|l|l|l|l|l|}
\hline \multicolumn{6}{|c|}{ DA ANOVA for Response Surface Quadratic Model in $\mathrm{HCl}$} \\
\hline Source & $\begin{array}{l}\text { Sum of } \\
\text { Squares }\end{array}$ & $\begin{array}{l}\text { Mean } \\
\text { Square }\end{array}$ & F Value & p-value & \\
\hline Model & 0.076 & 0.015 & 5.9 & 0.0258 & significant \\
\hline A-temperature & 0.011 & 0.011 & 4.36 & 0.0817 & \\
\hline B-period & $6.00 \mathrm{E}-06$ & $6.00 \mathrm{E}-06$ & $2.33 \mathrm{E}-03$ & 0.963 & \\
\hline AB & $2.87 \mathrm{E}-03$ & $2.87 \mathrm{E}-03$ & 1.12 & 0.3315 & \\
\hline $\mathrm{A}^{\wedge} 2$ & 0.02 & 0.02 & 7.76 & 0.0317 & \\
\hline Lack of Fit & $8.52 \mathrm{E}-03$ & $2.84 \mathrm{E}-03$ & 1.24 & 0.4332 & not significant \\
\hline
\end{tabular}

Table 5. Dimensional accuracy ANOVA for $\mathrm{HBr}$ etching.

\begin{tabular}{|l|l|l|l|l|l|}
\hline \multicolumn{5}{|c|}{ DA ANOVA for Response Surface Quadratic Model in $\mathrm{HBr}$} \\
\hline Source & Sum of Squares & $\begin{array}{l}\text { Mean } \\
\text { Square }\end{array}$ & F Value & $\begin{array}{l}\mathrm{p}- \\
\text { value }\end{array}$ & \\
\hline Model & 10.81 & 5.4 & 4.79 & 0.0384 & significant \\
\hline A-temperature & 1.13 & 1.13 & 1 & 0.3441 & \\
\hline B-period & 9.65 & 9.65 & 8.55 & 0.0169 & \\
\hline Lack of Fit & 7.6 & 1.27 & 1.48 & 0.4019 & not significant \\
\hline
\end{tabular}

Table 6. Dimensional accuracy ANOVA for $\mathrm{H}_{3} \mathrm{PO}_{4}$ etching.

\begin{tabular}{|l|l|l|l|l|l|}
\hline \multicolumn{5}{|c|}{ DA ANOVA for Response Surface Quadratic Model in $\mathrm{H}_{3} \mathrm{PO}_{4}$} \\
\hline Source & $\begin{array}{c}\text { Sum of } \\
\text { Squares }\end{array}$ & Mean Square & $\begin{array}{l}\mathrm{F} \\
\text { Value }\end{array}$ & p-value & \\
\hline Model & 0.41 & 0.14 & 1.95 & 0.0499 & significant \\
\hline A-temperature & $8.76 \mathrm{E}-03$ & $8.76 \mathrm{E}-03$ & 0.13 & 0.7321 & \\
\hline B-period & 0.062 & 0.062 & 0.88 & 0.03747 & \\
\hline AB & 0.36 & 0.36 & 5.22 & 0.0416 & \\
\hline Lack of Fit & 0.33 & 0.056 & 0.49 & 0.7866 & not significant \\
\hline
\end{tabular}




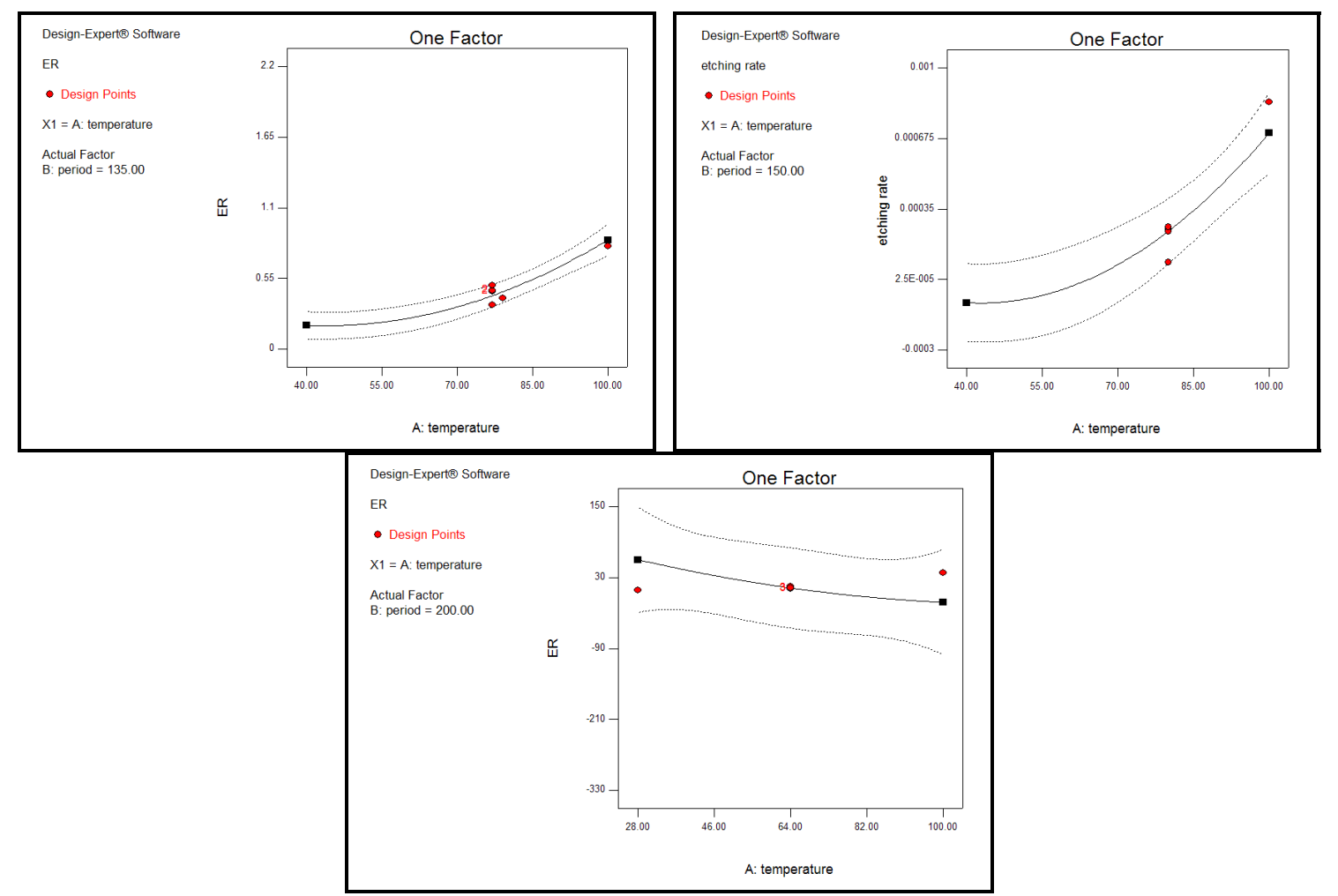

Fig.3. Etching rate vs etching temperature for: a) $\mathrm{HCl}$, b) $\mathrm{HBr}$, and c) $\mathrm{H}_{3} \mathrm{PO}_{4}$

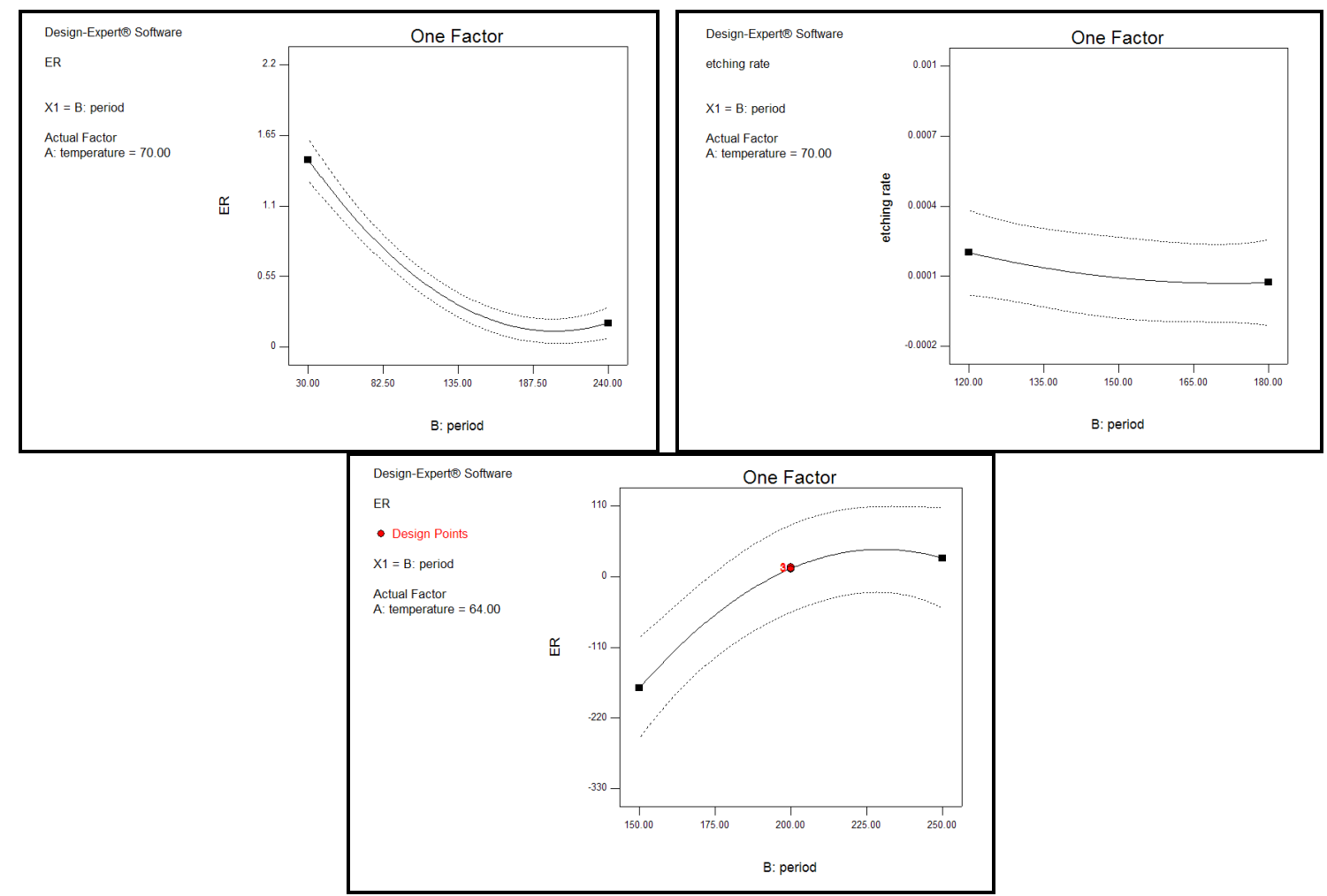

Fig.4. Etching rate vs etching duration for: a) $\mathrm{HCl}$, b) $\mathrm{HBr}$, and c) $\mathrm{H}_{3} \mathrm{PO}_{4}$ 


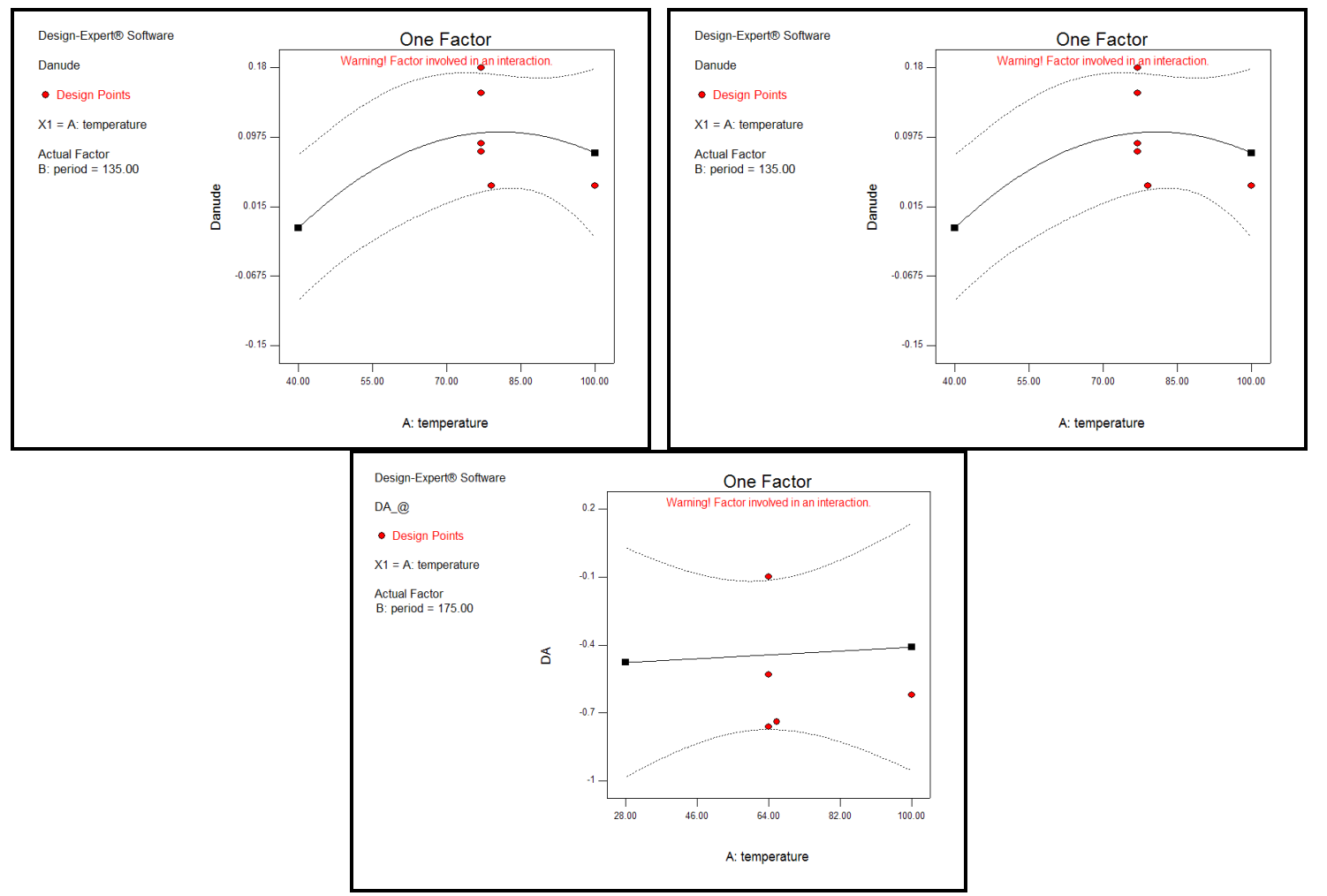

Fig.5. Dimensional accuracy vs etching temperature for: a) $\mathrm{HCl}$, b) $\mathrm{HBr}$, and c) $\mathrm{H}_{3} \mathrm{PO}_{4}$

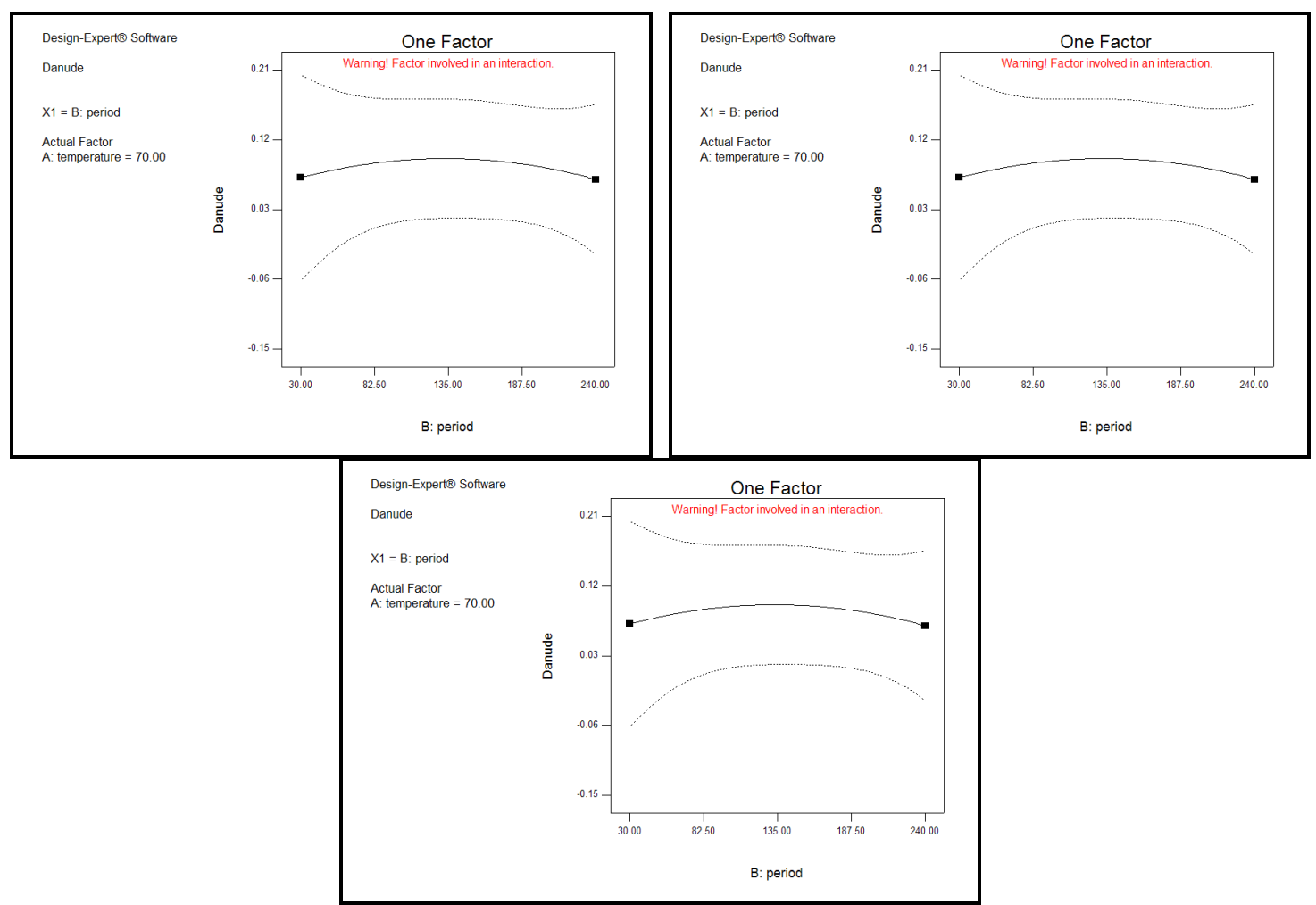

Fig. 6. Dimensional accuracy vs etching duration for: a) $\mathrm{HCl}, \mathrm{b}) \mathrm{HBr}$, and c) $\mathrm{H}_{3} \mathrm{PO}_{4}$

\section{Discussion}


Etching temperature. The etching rate and dimensional accuracy for all tested chemical etchant increase with increasing temperatures and this finding show good agreement with the theory. At high temperatures, more oxides are produced and this increased the reaction rate between ions. Tehrani et al. [13] also found that increase in oxidizing power causes a very rapid increase in etching rate. According to Arrhenius law [14], etching rate will increase as the temperature increase. This is due to the active energy, which is able to increase the chemical reaction in chemical etchant with increase temperature. In Arrhenius law, it is well known that chemical etching process is limited by either chemical reaction or by the transport of etchant molecules by diffusion; and, diffusion limited process are relatively insensitive to temperature . Many studies in the past [15-17] found temperature is one of the main variables in chemical etching process. Dimensional accuracy is closely dependent on etching rate, good dimensional accuracy might happen at any rate of etching. This is mainly cause by the defect or undercut happen, especially at high etching rate. In this research, it is found that dimensional accuracy shows a peak at temperature around $70-75^{\circ} \mathrm{C}$ and decreases dramatically after that. Isotropic wet etching uses here causes undercut happened at the decreased dimensional accuracy shown in fig. 5 because they erode the substrate equally in all directions $[11,18]$.

Etching duration. In most cases, etching duration significantly affects etching rate and dimension accuracy to some extent. Relationship of etching rate and etching duration are different as shown in fig. 4. With longer etching duration, it is increasing etching rate of $\mathrm{H}_{3} \mathrm{PO}_{4}$ etching but decreasing etching rate of $\mathrm{HCl}$ and $\mathrm{HBr}$ etching. In $\mathrm{HCl}$ etching, etching rate decreased with increasing period until 185 minutes and increased after that. $\mathrm{In}_{3} \mathrm{PO}_{4}$, etching rate show a positive slope with peak rate occurred at 220minutes and overetched occurs after that. These results are related to the different reaction that taken place between chemical etchants and MGC. Pits appear on the MGC surface at longer etching duration, which means that the sample was overetched and no longer in service. As indicated in previous research papers, it is found undercut occurred at longer etching duration or overetched [19]. Gaiseanu et al. [20] concluded that etching rate decreased with increasing etching duration in BN. They also concluded that relationship between etching rate and etching duration depended on the material properties and composition of BN.

Solution. It is clearly shown that etching rate and dimensional accuracy present different machinability in different type of chemical etchants. This occurs because of the chemical reaction between each substrate with designated chemical etchant. Insoluble materials are produced during the reaction and this caused low value of etching rate. This phenomena occurs when generated insoluble materials covered the reaction surface and blocked the reaction. William et al. $[16,21]$ mentioned that each substrate has to be chemically compatible to their etching solution in order to conduct the etching process. Cook et al. [22] showed the importance of chemical etchant. In this study, the best result is produced with $\mathrm{HCl}$ acid because it gives highest etching rate and dimensional accuracy with lower etching duration.

Optimization. Optimization is carried out with DE 7 and optimum values are shown in table 7 for each chemical etchant.

Table 7. Optimization

\begin{tabular}{|l|l|l|l|l|}
\hline Solution & Temperature $\left({ }^{\circ} \mathrm{C}\right)$ & Period $(\min )$ & ER $(\mathrm{g} / \mathrm{min})$ & DA (um) \\
\hline $\mathrm{HCl}$ & 100 & 70 & 1.522 & 0.0530 \\
\hline $\mathrm{HBr}$ & 100 & 150 & 0.863 & 0.0491 \\
\hline $\mathrm{H}_{3} \mathrm{PO}_{4}$ & 100 & 200 & 0.533 & 0.0122 \\
\hline
\end{tabular}

\section{Conclusion}


The effect of etching temperature, etching duration and chemical etchant are investigated in this study. The etching rate and dimensional accuracy are found to be very sensitive to chemical etchant and etching temperature. With a few numbers of testing, it is found that dimensional accuracy is relatively dependent on etching rate. CCD is successfully analyzed this experiment data. As a conclusion, generated results do able to estimate the chemical etching process.

\section{References}

[1] R. N. Katz, "Applications of high performance ceramics in heat engined design," Materials Science and Engineering vol. 71, pp. 227-249, 1985.

[2] L. Trutna, P. Spagon, T. Moore, S. Hartlye, and A. Hurwitz, "Engineering Statistics Handbook," C. Croarkin and P. Tobias, Eds.: NIST, 2003.

[3] J. Y. Thompson, S. C. Bayne, and H. O. Heymann, "Mechanical properties of a new mica-based machinable glass ceramic for CAD/CAM restorations," The Journal of Prosthetic Dentistry, vol. 76, pp. 619-623, 1996.

[4] A. Guedes, A. M. P. Pinto, M. Vieira, and F. Viana, "Multilayered interface in Ti/Macor machinable glass-ceramics joints," Materials Science and Engineering A, vol. 301, pp. 118-124, 2001.

[5] J. R. Sun, C. F. Yeung, K. Zhao, H. K. Wong, C. M. Xiong, and B. G. Shen, "Chemical etching and thickness effects on the resistive property of La2/3Ca1/2MnO3 films," Physica B, vol. 334, pp. 310-6, 2003.

[6] D. C. S. Bien, P. V. Rainey, S. J. M. Mitchel, and H. S. Gamble, "Chracterization of masking materials for deep glass micromachining," Journal of Microelectromech. Syst., vol. 13, pp. S34-S40, 2003.

[7] H. Maki, T. Ikoma, I. Sakaguchi, N. Ohashi, H. Haneda, J. Tanaka, and N. Ichinose, "Control of surface morphology of $\mathrm{ZnO}$ image by hydrochloric acid etching," Thin Solid Films, vol. 411, pp. 9195, 2002.

[8] T. Corman, P. Enoksson, and G. Stemme, "Deep wet etching of borosilicate glass using an anodically bonded silicon substrate as mask," Journal of Micromech. Microeng., vol. 8, 1998.

[9] Y. Saito, S. Okamoto, A. Miki, H. Inomata, T. Hidaka, and H. Kasai, "Fabrication of microstructure on glass surface using micro-indentation and wet etching process," Applied Surface Science, vol. 254, pp. 7243-7, 2008.

[10] Y. Saito, S. Okamoto, H. Inomata, and J. Kurachi, "Mechanism of etching rate change of aluminosilicate glass in HF acid with micro-indentation," Applied Surface Science, vol. 255, pp. 22904, 2008.

[11] Y. saito, S. Okamoto, I. Inomata, J. Kuranchi, T. Hidaka, and H. Kasai, "Micro-fabrication techniques applied to aluminosilicate glass surfaces: Micro-indentation and wet etching process," Thin Solid Films, vol. 517, pp. 2900-2904, 2008.

[12] C. G. K. S.W. Youn, "Maskless pattern fabrication on Pyrex 7740 glass surface by using nanoscratch with HF wet etching " Scripta Materialia, vol. 52, pp. 117-122, 2005.

[13] A. F. Tehrani and E. Imanian, "A new etchant for the chemical machining of St304," Journal of Materials Processing Technology, vol. 149, pp. 404-8, 2004.

[14] P. L. Houston, Chemical kinetics and reaction dynamics vol. 1: McGraw-Hill, 2001.

[15] E. Makino, T. Shibata, and Y. Yamada, "Micromachining of fine ceramics by photolithography," Sensors and Actuators A, vol. 75, pp. 278-288, 1999.

[16] K. R. Williams and R. S. Muller, "Etch rates for micromachining processing," Journal of Microelectromech. Syst., vol. 5, pp. 256-269, 1996.

[17] N. Prudhomme, D. Cacahu-Herreillat, P. Papet, and O. Cambon, "Gallium orthophoshate device manufacturing by chemical etching," Proceeding of 2003 IEEE International Frequency Control Symposium and PDA Exhibition pp. 688-693, 2003. 
[18] W. T. Harris, Chemical Milling: the Technology of Cutting Materials by Etching. Michigan: Claredon Press, 1976.

[19] Y. Hua, "Studies of a new chemical etching method - 152 Secco etch in failure analysis of wafer fabrication," Proceeding in International Conference on Software, pp. 20-26, 1998.

[20] F. Gaiseanu, D. Tsoukalas, J. Esteve, C. Postolache, D. Goustouridis, and E. Tsoi, "Chemical etching control during the self-limitation process by boron diffusion in silicon: analytical results," Proceeding of 1997 IEEE Semiconductor Conference, vol. 1, pp. 247-250, 1997.

[21] K. R. Williams, K. Gupta, and M. Wasilik, "Etch rates for micromachining processing-Part 2," Journal of Microelectromech. Syst., vol. 12, pp. 761-778, 2003.

[22] S. G. Cook, J. A. Little, and J. E. King, "Etching and microstructure of engineering ceramics," Materials Characterization, vol. 34, pp. 1-8, 1995. 